\title{
Prevalence of Obesity and Factors Leading to Obesity among High School Students of Pakistan
}

ANJUM HASHMI, ${ }^{1}$ JAMIL AHMED SOOMRO, ${ }^{2}$ KHALID SALEEM, ${ }^{3}$

\begin{abstract}
Background: At least 20 million children under the age of 5 years were overweight globally in year 2005. Childhood obesity prevalence has increased by three to four folds globally within past few decades. It is also becoming an important public health problem among Pakistani children due to changes in life style and other factors. This study is aimed to estimate the prevalence of obesity and the associated factors leading to obesity among school students urban city of Hyderabad.
\end{abstract}

Objective: To determine the Prevalence of obesity and factors leading to obesity among high school students of public and private schools of Hyderabad city Pakistan.

Methods: A Cross-sectional study was conducted from 0 I January 2008 to 30 June 2009 in Hyderabad. A total of 504 male and female students of class six to ten were selected through simple random sampling. They were interviewed by trained data collectors through physical activity and diet questionnaires. Anthropometric measurements were done with calibrated instruments using the age and sex specific BMI cut off points according to WHO growth reference. Data analysis was done on SPSS 16.

Results: The prevalence of overweight and obesity was $23 \%$ and 15\%, respectively, among the boys, while $16 \%$ and $8 \%$ respectively in girls. When adjusted for other factors multivariate model showed that the girls were protected against obesity, $O R=0.33(0.16-68)$. Odds ratios for the age groups showed that older children were also protected against obesity. Middle socioeconomic status tertile was more than 3 times more likely to be obese.

Conclusions: Childhood obesity is determined by the factors in the home, school and other physical environment and it is recommended that all the stakeholders should take relevant actions for the prevention of the problem.

Keywords: Obesity, students, Diet, Body Mass Index (BMI), schools, overweight, physical activity, waist to hip ratio.

\section{Introduction}

According to world health organization approximately 1.6 billion adults (age 15+) were overweight; and at least 400 million adults were obese in 2005, at least 20 million children under the age of 5 years were overweight globally in year 2005. ${ }^{1}$ Childhood obesity prevalence has increased by three to four folds globally within past few decades; the obesity epidemic has resulted due to sedentary life style and decline in physical activity. ${ }^{2-4}$ Many countries are paying a heavy price for this in the form of chronic diseases, such as diabetes mellitus and hypertension, at a younger age and mounting expenditure on the treatment of complications of chronic diseases. ${ }^{5}$ Pakistan stands among those countries which

1. Community Health Officer, Department of Community Health Prf Medical Center Karachi Pakistan, E-mail anjumhashmi61@hotmail.com

2. District Officer NMCH Program WHO Pakistan.

3. Medical Superintendent PINS Complex Hospital Nalore Islamabad.

Correspondence : Community Health Officer, Department of Community Health Prof. Medical Center Karachi Pakistan, E-mail anjumhashmi61@hotmail.com have the prevalence of obesity, among boys and girls, between $15 \%$ to $20 \%{ }^{6}$ Pakistan being a low income country faces the double burden of diseases and obesity is a major risk factor for a number of Non communicable Diseases. ${ }^{7}$

Although it is recommended that the school children should spend at least one hour of their curriculum time on moderate physical activity; the schools generally have ignored the importance of incorporating physical activity opportunities. ${ }^{8}$ Almost all food companies target children for their products which is basically "junk food" i.e. providing little nutrition but of high caloric content. Therefore the epidemic of obesity can be explained by the increased intake of diet rich in fat and sugars but low in vitamins, minerals and other micronutrients. ${ }^{10}$

Technology has also contributed to the epidemic of obesity; television watching time has been considered an important determinant of the obesity in children; firstly it leaves children physically inactive secondly television is the most used medium for food advertisements targeting children ${ }^{9}$.

Obesity as defined by the WHO is a condition of abnormal or excessive fat accumulation in adipose tissue, to the extent that health may be impaired. Body mass index (BMI) is a 
simple index of weight-for-height, the weight in kilograms divided by the square of the height in meters $(\mathrm{kg} / \mathrm{m} 2)^{10}$ cut off point of $30 \mathrm{~kg} / \mathrm{m} 2$ is recognized internationally as a definition of adult obesity and $25 \mathrm{~kg} / \mathrm{m} 2$ for overweight. Therefore, cutoff points related to age would better define childhood obesity ${ }^{11}$.

It is now proven that the risk factors for adult non communicable diseases particularly diabetes mellitus, ${ }^{12}$ Ischemic Heart Disease (IHD) and Hypertension (HTN) start early during childhood. In one major cohort study done on a sample of 276,835 children aged 7-13 years it was found that heavier children had greater chances of development of coronary health disease in adulthood. ${ }^{14,15}$ According to an estimate, obesity costs the National Health Services (NHS) of the United Kingdom directly around $£ 1$ billion and the UK economy a further $£ 2.3$ to $£ 2.6$ billion in indirect costs every year. U.K. and other European countries are therefore spending a huge amount of their national exchequer to deal with the issue of childhood obesity. ${ }^{13}$

Generally a sedentary life style is associated with obesity among children. A sedentary life include, most importantly, watching television and playing video games and surfing on the internet. Computer use, television watching ${ }^{9}$ for long periods of time and especially at the prime time when most food advertisements are shown. ${ }^{16,17}$

Obesity in children is also become a public health problem in countries like India has significant rise in the proportion of overweight and obese children has taken place, especially in the urban centers; ${ }^{18}$ Saudi Arabia has prevalence of overweight and obese school children boys $20 \%$ and girls $11 \%{ }^{19}$ and other countries in the gulf also have similar trends, for instance, about $16.5 \%$ and $16.9 \%$ of boys and girls, respectively are obese and overweight in United Arab Emirates. ${ }^{20}$ The study helped to formulate the recommendations for preventing the growing epidemic of obesity and factors related to it in a typical local setting.

\section{Methods}

A Cross-sectional study was conducted from 01 January 2008 to 30 June 2009 in urban city of Hyderabad. The Objective of study was to determine the Prevalence of obesity and factors leading to obesity among high school students of public and private schools of Hyderabad city Pakistan.

A total of 504 male and female students selected through simple random sampling. They were interviewed by trained data collectors through physical activity and diet questionnaires. Questionnaire was based on three sections; first, the variables on the socio-demographic factors, second, the variables on the physical activity and school and home environments conducive for physical activity and the last on the food frequency. The physical activity questionnaire was further consolidated and adapted by using the questions from the Youth Physical Activity Survey questionnaire of "The School Health Action, Planning and Evaluation SystemSHAPES" study of the University of the Waterloo Canada.

Anthropometric measurements were done with calibrated instruments using the age and sex specific BMI cut off points given by W.H.O. Obesity among the school children was the outcome/dependent variable. Cut off points given by the World Health Organization for the measurement of Obesity were used. In the new WHO growth reference for the school age children and adolescents, more than $85^{\text {th }}$ percentile (BMI Kg/height ${ }^{2}$ ) is equivalent to overweight and more than $95^{\text {th }}$ percentile $\left(\mathrm{BMI} \mathrm{Kg} /\right.$ height $^{2}$ ) is equivalent to obesity. $^{21}$

Waist circumference (WC) is also an important measurement especially of truncal obesity. Although there is no consensus about how to define obesity among children using waist circumference (WC). The cut-off points of WHR are around 0.9 for males and 0.8 for females. ${ }^{27}$

But clinical use the 98th percentiles is the suggested cut-off for obesity and the 91 st percentile is the cut-off for overweight (NICE.UK).$^{22}$ Ten data collectors were hired and trained in workshop for preparation of the field work, to liaison with the school administration and gathering of the lists of the schools and children, signing up of assent forms by the parents, pretesting and final questionnaire administration and anthropometric measurements. The anthropometric tools used are WS 2032 Mechanical weight scale with height scale of Narang Medical Limited and BMI 60 Tape of The Perfect Measuring Tape Company.

For the calculation of the sample size to keep the secondary objective in consideration we calculated sample size for two population proportions through using Epi info version 6 . For associated factors $31 \%$ prevalence of mothers of the non obese school children with low education, $23.76 \%$ prevalence of non obese children in upper socioeconomic status and $17 \%$ prevalence of non obese children of working mothers (expected frequency of disease among non diseased) was considered. ${ }^{19}$

The final sample size was given by the variable mothers' education because it gave the largest sample of all the independent variables. To see the association of mothers education with the obesity in children we took a confidence level of $95 \%$, power of $80 \%$, the ratio of exposed children (whose mothers are illiterate) to unexposed children (children whose mothers have at least five years of education) and 
the prevalence of obesity among children of educated mothers of $31 \%$ the sample size came to be 336 with 114 in unexposed arm and 228 among exposed arm. Using a design effect of 1.5 the final sample size came out to be 504 (336*1.5).

Data was analyzed in the statistical package for social sciences (SPSS) version 16.0. Descriptive analysis was conducted for calculating mean and standard deviations for continuous variables and proportions were calculated for categorical variables such as level of education of parents, gender and type of school. In inferential analysis, at a 5\% level of significance (á), t-test was used. Multiple logistic regression analysis was used for adjusting the confounders.

Results were available for 501 subjects out of the 504 subjects. Three forms were not eligible for the analysis due to the incompleteness of the data. Analysis of the results is presented into sequential groups. These groups are descriptive variables, univariate logistic regression analysis followed by the multivariate logistic regression analysis. Each of these groups are again subdivided and ordered into most understandable categories namely the socio-demographic variables, overweight and obesity descriptive variables, variables related to determinants of obesity in the participants, variables on the food behavior of the students and finally the parental/home factors promoting obesity among children.

\section{Results}

Mean Age of the participants was 13.8 years ( $\mathrm{S} . \mathrm{D}=1.6)$. The ratio of boys to girls in the sample was almost equal 255 $(50.9 \%)$ boys and $246(49.1 \%)$ girls. (Table-I)

\section{Table-I}

Socio-demographic characteristics high school students of Hyderabad

\begin{tabular}{lcc}
\hline Variables & Frequency & Percent \\
\hline Gender (n=501) & & \\
Boys & 255 & 50.9 \\
Girls & 246 & 49.1 \\
Age (n=501) Mean ( SD) 13.8 years (1.6) & & \\
Socioeconomic Status (n=370) & & \\
Lower tertile & 123 & 32.8 \\
Middle tertile & 124 & 33.1 \\
Upper tertile & 123 & 34.1 \\
Type of School (n=501) & & \\
Private & 399 & 79.6 \\
Government & 102 & 20.4 \\
\hline
\end{tabular}

The prevalence of overweight ( $>85$ th Percentile) and obesity $\left(>95^{\text {th }}\right.$ percentile) was $23 \%$ and $15 \%$ among the boys respectively whereas in girls the prevalence of overweight and obesity was $16 \%$ and $8 \%$ respectively (Table-II).
Table-II

Description of overweight and obesity by sex of high school students of Hyderabad $(n=501)$

\begin{tabular}{lcc}
\hline $\begin{array}{l}\text { Obesity And Overweight } \\
\text { Overweight }\end{array}$ & $\begin{array}{c}\text { Boysn } \\
(\%)\end{array}$ & $\begin{array}{c}\text { Girls n } \\
(\%)\end{array}$ \\
\hline Yes $(>85$ th Percentile BMI) & $59(23 \%)$ & $39(16 \%)$ \\
No $(<85$ th Percentile BMI) & $196(77 \%)$ & $207(84)$ \\
Obesity & & \\
Yes $(>95$ th Percentile BMI) & $38(15 \%)$ & $20(8 \%)$ \\
No $(<95$ th Percentile BMI) & $217(85 \%)$ & $226(92 \%)$ \\
Waist To Hip Ratio (WHR) & & \\
WHR $>0.8$ & NA & $35(14 \%)$ \\
WHR $<0.8$ & NA & $211(86 \%)$ \\
WHR $>0.9$ & $177(69 \%)$ & NA \\
WHR $<0.9$ & $78(11 \%)$ & NA \\
Waist Circumference; Mean (SD) & $75.509(10.46)$ & $72.23(8.52)$ \\
Hip Circumference; Mean (SD) & $86.03(10.09)$ & $85.24(8.95)$ \\
\hline
\end{tabular}

Univariate analysis (Table-III) was significant (P-Value $<0.25$ ) for the starch, vegetables, fruit and dairy variables. Those variables which had $p$-value less than 0.25 were eligible entered in the multivariate logistic regression analysis. $\mathrm{P}$ value for the dichotomous variables and Omnibus tests of model coefficients' $p$ value is given for the variables containing more than 2 categories.

These along with the other insignificant but biologically plausible variables in the food frequency, were entered in the multivariate analysis.

In multivariable analysis are other independent variables including; school gives awards in non-competitive sports, ate lunch at some restaurant in last week, food frequency variables specifically, dairy foods, starch, vegetables the pvalue $>0.05$.

Males showed a higher risk of obesity as compared to females. Specifically the females were $67 \%$ less likely to be obese than males, (OR.0.33). This gender relationship with the outcome improved from $35 \%$ in the univariate to $65 \%$ in the multivariate analysis. Also those in the older age groups were more protected against obesity than those in the younger age groups. For instance those in the 14.4-15.3 age range were 82 percent $(\mathrm{OR}=0.18)$ less obese than those in the 9.4-12.1 age range. However the omnibus $P$ value was borderline insignificant $(0.061)$ for the age variable. Those in the middle Socioeconomic status tertile were 3.4 times more likely to be obese than those in the lower tertile ( $P$ value $=0.004)$. Finally those who were eating fruit more than 4 times a week were 55\% (OR 0.45) less obese than those who ate less than 4 times a week $(P$ value $=0.02)$. (Table-IV) 
Table-III

Univariate analysis: Factors related to "food behavior" of high school students of Hyderabad (n=-501)

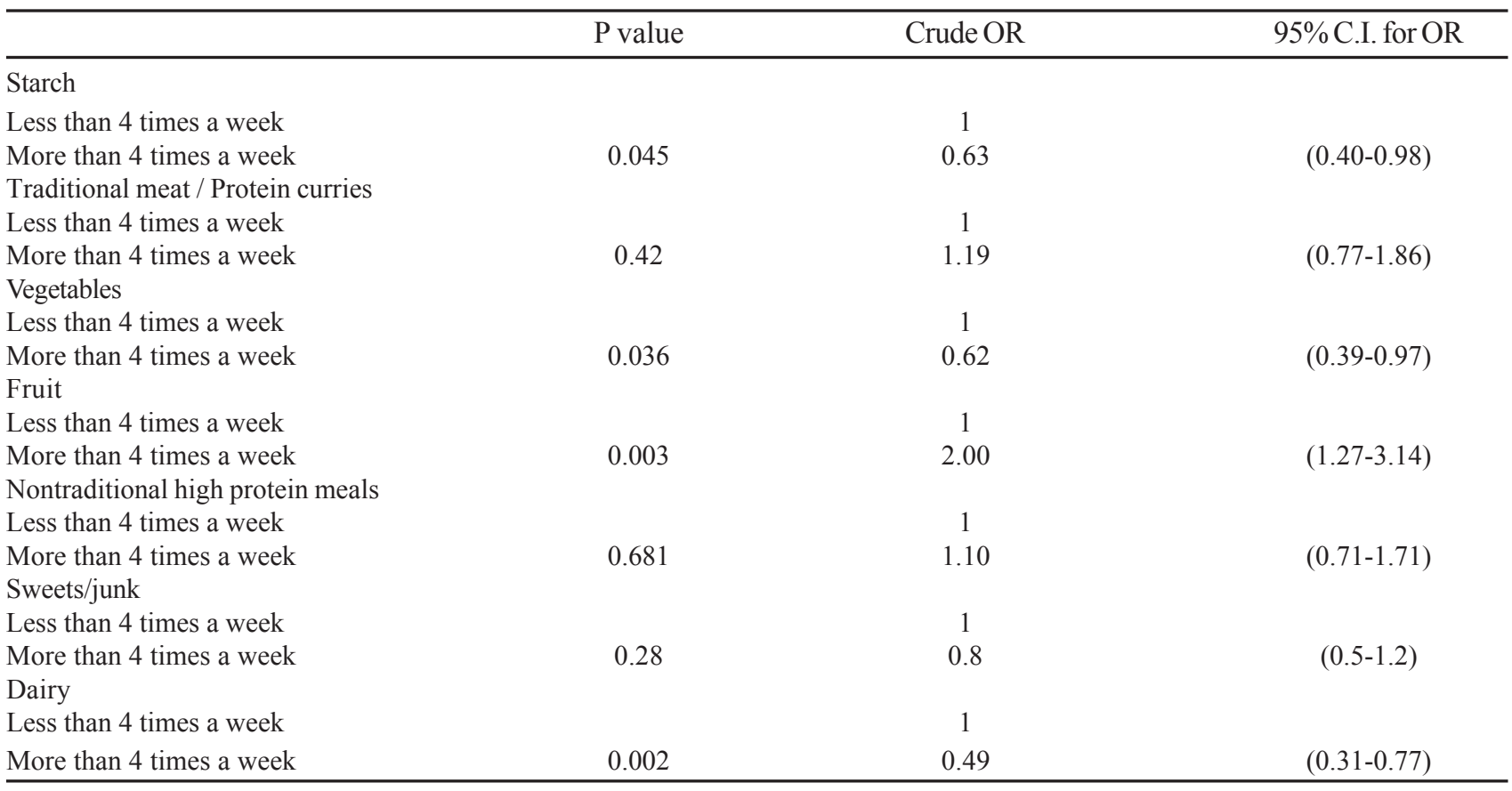

Table-IV

Univariate analysis: Factors related to "food behavior" of high school students of Hyderabad (n=-501)

\begin{tabular}{|c|c|c|c|c|}
\hline & $\mathrm{P}$ value & OR & CI for OR & \\
\hline \multicolumn{2}{|l|}{ Eat at a fast food place or restaurant last week? } & Never & & 1.00 \\
\hline 1-3 Times & 0.007 & 1.85 & $(1.19-2.89)$ & \\
\hline Brought lunch from home to school last week? & & Never & & 1.00 \\
\hline 1-3 Times & 0.170 & 0.63 & $(0.33-1.22)$ & \\
\hline Ate lunch at home on a school day last week? & & Never & & 1.00 \\
\hline 1-3 Times & 0.705 & 0.85 & $(0.38-1.94)$ & \\
\hline \multicolumn{5}{|l|}{ Ate breakfast last week? } \\
\hline Never & & 1.00 & & \\
\hline 1-3 Times & 0.609 & 0.85 & $(0.46-1.58)$ & \\
\hline Meals or snacks while watching television last week? & & Never & & 1.00 \\
\hline 1-3 Times & 0.899 & 0.97 & $(0.57-1.63)$ & \\
\hline \multicolumn{5}{|l|}{ Breakfast } \\
\hline With parents & & 1 & & \\
\hline Alone & 0.284 & 1.27 & $(0.82-1.98)$ & \\
\hline \multicolumn{5}{|l|}{ Lunch } \\
\hline With parents & & 1 & & \\
\hline Alone & 0.702 & 1.10 & $(0.68-1.78)$ & \\
\hline \multicolumn{5}{|l|}{ Dinner } \\
\hline \multicolumn{5}{|l|}{ With parents } \\
\hline Alone & 0.797 & 0.93 & $(0.55-1.59)$ & \\
\hline \multicolumn{5}{|c|}{ Any fast food company open stall in school in last six months } \\
\hline Yes & & 1.00 & & \\
\hline No & 0.375 & 0.81 & $(0.51-1.29)$ & \\
\hline $\begin{array}{l}\text { Does the school arrange trips to fast food } \\
1.00\end{array}$ & & & No & \\
\hline Yes & 0.695 & 1.10 & $(0.66-1.84)$ & \\
\hline Number of trips to fast food in last six months & 0.195 & 1.12 & $(0.94-1.33)$ & \\
\hline
\end{tabular}


Table-V

Multivariate Logistic Regression Analysis for Obesity and Overweight versus Normal Weight with Diet of high school students of Hyderabad $(n=-501)$

\begin{tabular}{|c|c|c|c|}
\hline & Crude OR $(95 \% \mathrm{CI})$ & Adjusted OR (95\% C.I.) & P-value(MVA) \\
\hline \multicolumn{4}{|l|}{ Gender } \\
\hline Males & 1.00 & 1.00 & \\
\hline Females & $0.65(0.41-1.01)$ & $0.33(0.16-68)$ & 0.002 \\
\hline \multicolumn{4}{|c|}{ Age(decimal points are months) } \\
\hline 9.4-12.2 Years & 1.00 & 1.00 & 0.061 \\
\hline 12.3-13.3 Years & $0.63(0.32-1.22)$ & $0.47(0.17-1.27)$ & \\
\hline 13.4-14.5 Years & $0.43(0.22-0.87)$ & $0.45(0.16-1.27)$ & \\
\hline 14.6-15.3 Years & $0.40(0.2-0.83)$ & $0.18(0.05-0.56)$ & \\
\hline 15.4-17.6 Years & & $0.80(0.42-1.52)$ & $0.60(0.21-1.67)$ \\
\hline \multicolumn{4}{|l|}{ Socioeconomic Status } \\
\hline Lower tertile & 1.00 & 1.00 & 0.004 \\
\hline Middle tertile & $2.22(1.14-4.33)$ & $3.43(1.49-7.93)$ & \\
\hline Upper tertile & $1.62(0.81-3.22)$ & $0.12(0.01-1.00)$ & \\
\hline \multicolumn{4}{|l|}{ Fruit } \\
\hline Less than 4 times a week & 1.00 & 1.00 & \\
\hline More than 4 times a week & $2.0(1.27-3.14)$ & $0.45(0.22-0.91)$ & 0.02 \\
\hline
\end{tabular}

\section{Discussion}

A high prevalence of overweight and obesity among the sampled population was the main finding of our study. The prevalence of overweight ( $>85$ th Percentile) and obesity $\left(>95^{\text {th }}\right.$ percentile) was $23 \%$ and $15 \%$ among boys, whereas in girls the prevalence of overweight and obesity was $16 \%$ and $8 \%$ respectively. Therefore girls were less overweight and obese than boys. A possible mechanism of boys being more obese and overweight than the girls is that the boys are perhaps more mobile and go getting as far as their reach toward most types of foods is concerned. This is particularly important in our scenario because the girls culturally suffer from restrictions of social mobility as they grow older. Additionally the low status of women in our country and consequent preference of boys in every matter including provision of meals might also have contributed towards a girl with lesser chances of her being obese.

WHR is another measure of central obesity along with BMI. Although the WHR is not a very good measure of the risk of cardiovascular diseases among young children as it is in adults but a significant proportion of girls (86\%) and boys (11\%) had abnormal WHR. Participants were spending a large proportion of their time on media and this included the time spent on any or all of computer, internet surfing, playing video games, and watching movies watching television.
Specifically they were spending a mean of 20 hours (SD 13.9) on media on a typical week.

Our study showed that those students who were eating fruit more than 4 times a week were (55\%) less obese. Students who participated in games outside schools are protected against obesity ( $\mathrm{P}$ value $=0.552$ ). Those who were bringing lunch from home to school are shielded against obesity ( $\mathrm{P}$ value 0.170$)$. Those who were eating at some fast food outlet rather than at home are more obese ( $\mathrm{P}$ value 0.007$)$. Our multivariate model for main physically activity related variables showed that the girls were less obese than the boys and this relationship was highly statistically significant ( $\mathrm{P}$ value $<0.000, \mathrm{OR}=0.33$, C.I. 0.16-68). Those in the middle socioeconomic tertile were 3.43 times more obese than those in the lower tertile.

Our finding that boys are more overweight and obese than girls is consistent with other studies. For instance in one study in USA they used data from National Health and Nutrition Examination Surveys (NHANES) and though the cut off criteria used were different but the prevalence of obesity was higher among boys than in girls (4.6\% vs. 2.9$)^{24}$. The study on Turkish children, mentioned earlier, showed that the obesity was prevalent among boys in much greater proportions than in girls ${ }^{23}$. 
Our study found that children belonging to the middle income families are more obese than those from the poor families. A recent publication from India derived data from the National Family Health Surveys (from 1992 to 2006) showed that those in the higher income classes were more likely to be obese than those in the lower income groups. Their data showed a consistent increase in the rates in the obesity mainly in the urbanized populations. ${ }^{25}$

As far as diet is concerned our multivariate model is in conformity with other scientific evidence that eating healthy diet, particularly fruit protects against obesity. ${ }^{26}$

Our study consolidates and confirms the results of similar studies from many other developed as well as developing countries. A high prevalence of overweigh and obese children in a typical Pakistani population clearly shows that the childhood obesity epidemic has already spread to our country.

A possible explanation for the occurrence of high prevalence of obesity among middle income group and absence of obesity among the children belonging to lower and upper income class is that the lower income group has minimal purchasing power as far as foods particularly energy dense foods is concerned on the other hand the upper class is more aware of the role of diet and the physical activity and remaining fit.

\section{Conclusion}

This study draws conclusion on the increasingly high burden of overweight and obesity among the children, particularly living in the urban setting of Pakistan. Furthermore obesity prevalence was highest among the boys, children belonging to the middle income families and those in the younger age groups. The determinants of the obesity lie within the home and school environment and the overall socio-cultural phenomena. Children are spending an alarmingly large part of their daily time on sedentary activities, mostly on television. Having minimal physical activity opportunities both at school and home and easier access to energy rich fast foods were found to be the major determinants of obesity in our study. Finally the consumption of fruits was associated with protection against obesity; a factor that emphasizes towards healthier eating in daily life.

\section{Acknowledgements}

Our heartiest acknowledgements to the education department Hyderabad and heads and staff of all school involved in providing every possible administrative help.

\section{Conflict of Interest: None}

\section{Funding: None}

\section{References}

1. World Health Organization.http://www.who.int/ dietphysicalactivity/childhood/en/

2. Costa RF, Cintra Ide P, Fisberg M. Prevalence of overweight and obesity in school children of Santos city, Brazil. Arq Bras Endocrinol Metabol 2006; 50(1):60-7.

3. Figueroa-Colon R, Franklin FA, Lee JY, Aldridge R, Alexander L. Prevalence of obesity with increased blood pressure in elementary school-aged children. South Med J 1997; 90(8):806-13.

4. Fima Lifshitz. Obesity in Children, J Clin Res Pediatr Endocrinol. 2008 December; 1(2): 53-60.

5. Singh AK, Maheshwari A, Sharma N, Anand K. Lifestyle associated risk factors in adolescents. Indian J Pediatr 2006; 73(10):901-6.

6. IASO. The International Association for the Study of Obesity. 2009-10,Portland Place LondonW1B1LY,UK.

7. Pappas G, Akhtar T, Gergen PJ, Hadden WC, Khan AQ. Health status of the Pakistani population: a health profile and comparison with the United States. Am J Public Health 2001; 91(1):93-8.

8. Adams J. Trends in physical activity and inactivity amongst US 14-18 year olds by gender, school grade and race, 19932003: evidence from the youth risk behavior survey. BMC Public Health 2006; 6:57.

9. World Health Organization Obesity and overweight, Fact sheets $\mathrm{N}^{*}$ 311, March 2011. http://www.who.int/en/

10. Cheng TO. Fast food, automobiles, television and obesity epidemic in Chinese children. Int J Cardiol 2005; 98(1): $173-4$.

11. Jones SE, Merkle SL, Fulton JE, Wheeler LS, Mannino DM. Relationship between asthma, overweight, and physical activity among U.S. high school students. J Community Health 2006; 31(6):469-78.

12. Freedman DS, Dietz WH, Srinivasan SR, Berenson GS. Risk factors and adult body mass index among overweight children: the Bogalusa Heart Study. Pediatrics 2009; 123(3):750-7.

13. House of Commons Health Committee, Third Report of session 2010-11, Department of Health publications, UK.

14. Anderson SE, Whitaker RC. Prevalence of obesity among US preschool children in different racial and ethnic groups. Arch Pediatr Adolesc Med 2009; 163(4):344-8.

15. Hering E, Pritsker I, Gonchar L, Pillar G. Obesity in Children Is Associated With Increased Health Care Use. Clin Pediatr (Phila) 2009. 
16. Fister K. Junk food advertising contributes to young Americans' obesity. Bmj 2005; 331(7530):1426.

17. Ingleby R, Prosser L, Waters E. UNCROC and the prevention of childhood obesity: the right not to have food advertisements on television. J Law Med 2008; 16(1): 49-56.

18. Marwaha RK, Tandon N, Singh Y, Aggarwal R, Grewal K, Mani K. A study of growth parameters and prevalence of overweight and obesity in school children from delhi. Indian Pediatr 2006; 43(11):943-52.

19. Al-Saeed WY, Al-Dawood KM, Bukhari IA, Bahnassy A. Prevalence and socioeconomic risk factors of obesity among urban female students in Al-Khobar city, Eastern Saudi Arabia, 2003. Obes Rev 2007; 8(2):93-9.

20. Al-Haddad F, Al-Nuaimi Y, Little BB, Thabit M. Prevalence of obesity among school children in the United Arab Emirates. Am J Human Biol 2000; 12(4):498-502.

21. World Health, Organization. Growth reference data for 5-19 years. 2007 [cited; Available from: http:/www.who.int/ growthref/who2007_bmi_for_age/en/index.html

22. McCarthy HD, Jarrett KV, Crawley HF. The development of waist circumference percentiles in British children aged 5.0-16.9 y. Eur J Clin Nutr 2001; 55(10):902-7.
23. de Wilde JA, van Dommelen P, Middelkoop BJ, Verkerk $\mathrm{PH}$. Trends in overweight and obesity prevalence in Dutch, Turkish, Moroccan and Surinamese South Asian children in the Netherlands. Arch Dis Child 2009.

24. Skelton JA, Cook SR, Auinger P, Klein JD, Barlow SE. Prevalence and Trends of Severe Obesity among US Children and Adolescents. Acad Pediatr 2009.

25. Wang Y, Chen HJ, Shaikh S, Mathur P. Is obesity becoming a public health problem in India? Examine the shift from under- to overnutrition problems over time. Obes Rev 2009; 10(4):456-74.

26. Kubik MY, Lytle L, Fulkerson JA. Fruits, vegetables, and football: findings from focus groups with alternative high school students regarding eating and physical activity. J Adolesc Health 2005; 36(6):494-500.

27. H Ito, K Nakasuga, A Ohshima, T Maruyama, Y Kaji, M Harada, M Fukunaga, S Jingu M Sakamoto. Detection of cardiovascular risk factors by indices of obesity obtained from anthropometry and dual-energy X-ray absorptiometry in Japanese individuals International Journal of Obesity 2003; 27: $232-237$. 